\title{
Economic Analysis and Environmental Impacts of a Hybrid PV System in Arid Climate Considering Different Types of Solar Trackers
}

\author{
Yahya Z. Alharthi, Mahbube K. Siddiki, Ghulam M. Chaudhry \\ Department of Computer Science \& Electrical Engineering, University of Missouri-Kansas City, Kansas City, USA \\ Email: yza6x6@mail.umkc.edu, siddikim@umkc.edu,chaudhryg@umkc.edu
}

How to cite this paper: Alharthi, Y.Z., Siddiki, M.K. and Chaudhry, G.M. (2018) Economic Analysis and Environmental Impacts of a Hybrid PV System in Arid Climate Considering Different Types of Solar Trackers. Smart Grid and Renewable Energy, 9, 199-214.

https://doi.org/10.4236/sgre.2018.910013

Received: September 27, 2018

Accepted: October 26, 2018

Published: October 29, 2018

Copyright $\odot 2018$ by authors and Scientific Research Publishing Inc. This work is licensed under the Creative Commons Attribution International License (CC BY 4.0).

http://creativecommons.org/licenses/by/4.0/

(c) (i) Open Access

\begin{abstract}
This paper presents a study aimed at evaluating and comparing the performance of six different tracking systems for photovoltaic (PV) with diesel-battery hybrid system in arid climate of Kingdom of Saudi Arabia (KSA). The study considered various technical and economic factors including system net present cost (NPC), levelized cost of energy (LCOE), and PV power generation using energy analysis and microgrid design software "HOMER". It also presents an overview of the current electricity production and demand in the Kingdom. The weather data used in this study have been collected from the new solar atlas launched by King Abdullah City for Atomic and Renewable Energy (KACARE). The selected solar resource monitoring station for this study is located near to Riyadh city and has an annual average daily total irradiation of $6300 \mathrm{~W} / \mathrm{m}^{2} /$ day. The study shows that, for stand-alone PV system in the vicinity of Riyadh city, tracking system is economically better than fixed angle system. Among the considered tracking systems, VCA system is the most preferable as it has low NPC and LCOE values with a high return on investment (ROI) as well as low carbon dioxide $\left(\mathrm{CO}_{2}\right)$ emissions due to a high renewable energy penetration.
\end{abstract}

\section{Keywords}

Renewable Energy, Solar Power, Hybrid PV System, Solar Trackers, HOMER System Planning

\section{Introduction}

Currently, most of the power production worldwide is generated from conventional power plants using fossil fuels like natural gas, oil, and coal [1]. The major disadvantages of the continued use of fossil fuels as primary energy sources are 
the environmental pollution that has an extremely negative impact on human health, constant fluctuation in prices, and the fact that such usage causes fuel depletion [2]. In this context, sources of renewable energy can have a significant impact in the energy sector, and they are considered an applicable choice for combination with typical fossil fuels power plants. Presently, $24 \%$ of the worldwide power production is represented by Renewable Energy (RE) and solar power represents $1.5 \%$ out of the total RE production [3]. The vast majority of renewable energy resources are clean and replenished sources. Among Renewable Energy Source (RES) technologies, solar power has shown a significant impact in power generation. A solar photovoltaic PV system can directly transfer the irradiation from the sun into electricity, and globally, it is one of the highest growing technologies among other types of renewable energy [4]. Figure 1 shows the solar PV global capacity and annual additions for 2006-2016. The cost of this technology has decreased gradually, and it is anticipated that it will continue to decrease in the future. The Kingdom of Saudi Arabia is a leading oil producer and famous for its arid climate focusing more on producing energy from renewable resources particularly from solar.

The demographic progression and economic growth in the kingdom increased spending on the development of conventional power plants in order to meet the national energy demand. In 2003, the Saudi Electricity Company (SEC) report showed that the maximum load of the national grid was $26.2 \mathrm{GW}$. In 2016, the total capacity of electricity generation, reached more than $74 \mathrm{GW}$, and it is expected to reach more than $100 \mathrm{GW}$ by 2030 due to both rapid population increases and economic growth [6] [7]. The yearly reports of the Electricity and Cogeneration Regulatory Authority (ECRA) show the growth of load and capacity generation during the last two decades in Saudi Arabia [8]. Also, the latest report of electric data provided by the SEC showed that the total number of customers in the year 2000 was 3,622,390 and recorded an average annual growth of 5.4\% from 2000 to 2014. For this reason, a renewable energy power for any application such as houses, universities and colleges, and industries not only have a

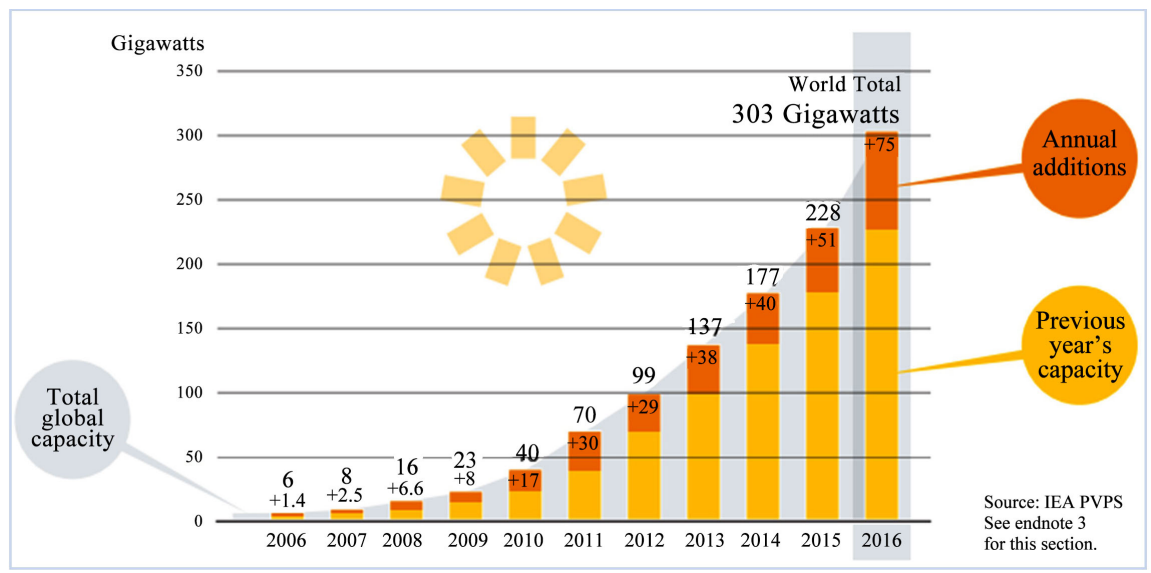

Figure 1. Solar PV global capacity and annual additions, 2006-2016 [5]. 
significant impact on reducing the dependence on fossil fuel as the primary energy source, but also on the prices of electricity bills and the levels of $\mathrm{CO}_{2}$ emissions.

Regarding solar power, several analytical studies to explore solar resources in KSA have been done previously. A study conducted by Erica et al. [9] summarized 12 months of solar resource measurement data for 30 stations, which KACARE installed across the kingdom. They analysed the Global Horizontal Irradiance (GHI), Direct Normal Irradiance (DNI), and Diffuse Horizontal Irradiance (DHI) data, based on one-minute measurements. Arif et al. [10] addressed the solar energy future aspects and the applications of solar power along with different studies conducted in the same field with the aim of establishing energy polices for KSA [11] [12]. In addition, Almarshoud [13] presented a review of the photovoltaic system for 32 sites of solar resources across the kingdom using three modes of a sun tracking system. That study showed a high productivity of energy and the difference in percentages of using a fixed tilt angle, and one-axis and two-axis tracking modes for the 32 sites. A.M. Ramli et al. [14] conducted experimental investigations to study the effect of weather conditions on a PV output power production using a simple rule-based model. This study came up with results presented as a percentage and showed the significant effect of dust, rain, and clouds on a PV panel's efficiency. Hassan et al. [3] conducted a study aimed to evaluate the performance of different types of trackers in a grid-connected PV system at the city of Makkah. The study showed the PV power production compared to grid purchased as well as the best tracking system from technical and economical point of view. The literature review shows the potential of solar resources based on the data of the Renewable Resource Monitoring and Mapping (RRMM) program, which KACARE provided, and other data of local sites in the KSA.

For the generation of electricity with great efficiency and reliability, a co-generation or hybrid system is recommended and have proven their usefulness [2] [15]. Hybrid renewable energy system commonly contains two or more combined renewable energy systems and can be used with conventional power plants to increase system efficiency and meet load demands [16]. However, renewable energy hybrid systems cannot work efficiently in some areas due to a lack of any type of natural resources. Therefore, using one type of renewable energy system that has sufficient resources can be more profitable than using a hybrid system. As an example, the use of a PV system instead of a PV-wind hybrid system is the chosen selection of this paper.

One of the main disadvantages of using only a PV system is its intermittent nature, since it causes power outages due to the insufficient solar irradiance during the day [17]. Hence, a diesel generator or battery bank can work as a backup system. The power produced by users can be used for their load, and also, the excess electricity can provide an additional income and that depends on the type of PV system, whether it is a stand-alone or grid connected power sys- 
tem [18].

In order to develop a stand-alone power system model to analyze the power production and identify the best economic configuration of PV with a battery bank and diesel generator, energy engineers or researchers typically use some commercial and free software like HOMER, TurnSys, System Advisor Model (SAM), RETScreen etc. [17]. The software Hybrid Optimization of Multiple Electric Renewables (HOMER) developed by the National Renewable Energy Laboratory (NREL) has been chosen for this study, as it is found to be the most useful in handling different types of analysis compared to other renewable energy analysis software [19] [20].

The primary observation by the authors shows that most of the existing research work in KSA focuses on the evaluation of renewable energy resources specifically the solar PV. One very important missing aspect is to investigate the effect of using different PV trackers on the system power production, environmental impacts, and economic attractiveness.

The aim of this paper is to do a comparative study of different PV tracking systems as well as investigating their environmental impacts beside the technical and economic aspects. This study additionally improvs the body of knowledge about, techno-economic analysis, environmental impacts, technical performance of renewable energy, and stand-alone hybrid PV system using different tracking systems with different time adjustments. The rest of this paper is organized as follows. Section 2 reflects our data and method of analysis; Section 3 offers our results and discussions; and Section 4 is the conclusion and future work.

\section{Data and Method of Analysis}

The monthly average GHI of the selected location (Longitude 46.4373, Latitude 24.5284) is downloaded from KACARE for three years starting from Jan 2014 to Dec 2016. The daily solar irradiation ranges between $4.150 \mathrm{kWh} / \mathrm{m}^{2}$ and 8.158 $\mathrm{kWh} / \mathrm{m}^{2}$; whereas, the annual average daily solar irradiation for this area is 6.3 $\mathrm{kWh} / \mathrm{m}^{2}$ as illustrated in Figure 2. From April to September, the GHI surpasses the average and reaches its peak in June and July. The remaining months, specifically November, December, and January, have low solar irradiation compared to the second and third quarters of the year. System optimization and method of analysis is represented by the flowchart in Figure 3. It starts with selecting the solar resource data as input, followed by simulation and optimization, and desired result at the end.

The hypothetical load considered in this study is a large residential load with a daily consumption of $90 \mathrm{~kW} /$ day located in the vicinity of Riyadh city. Beside the load, the system consists of four other components: the generator, DC to AC converter, solar PV array, and battery system as presented in Figure 4. The weather input data were provided by NASA's Surface meteorology and Solar Energy database along with other real data that were collected in the early stages of this project from KACARE. Figure 5 shows the hourly electric load for this 
system and the peak load that occurs during July. The stand-alone PV system model has been designed and followed by technical and economic investigation for the studied configurations.

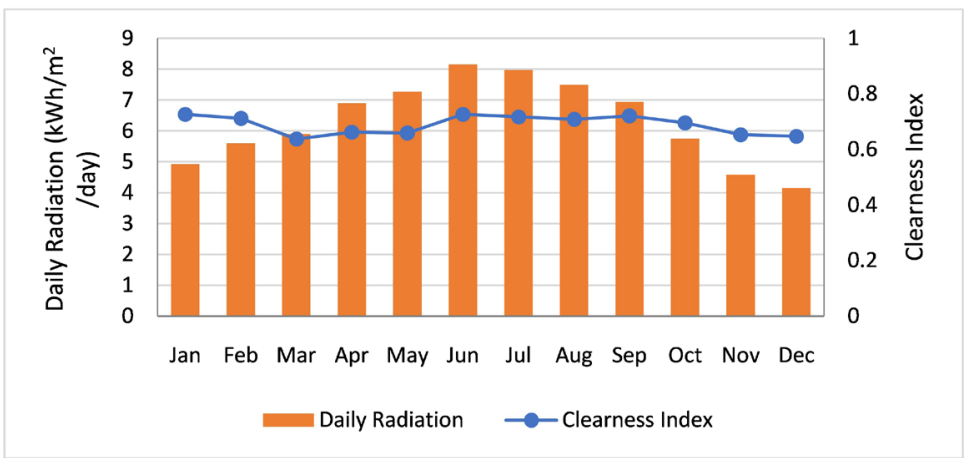

Figure 2. The monthly average global horizontal irradiance GHI in Riyadh.

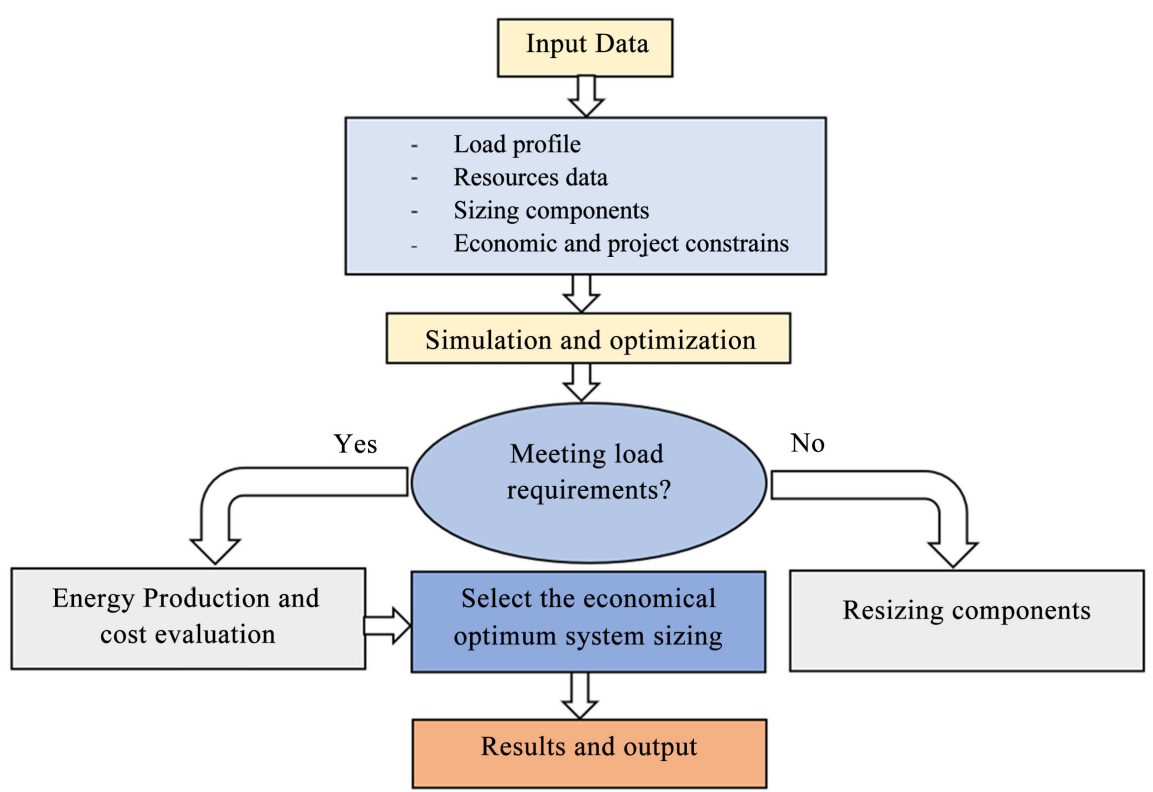

Figure 3. Flowchart of the study.

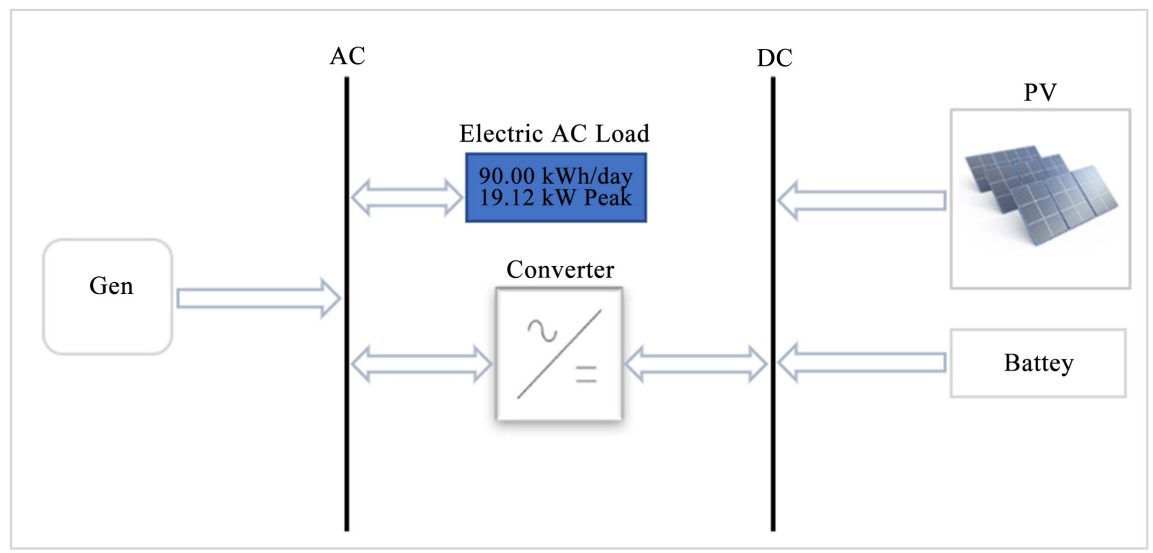

Figure 4. Design configuration of stand-alone PV system. 


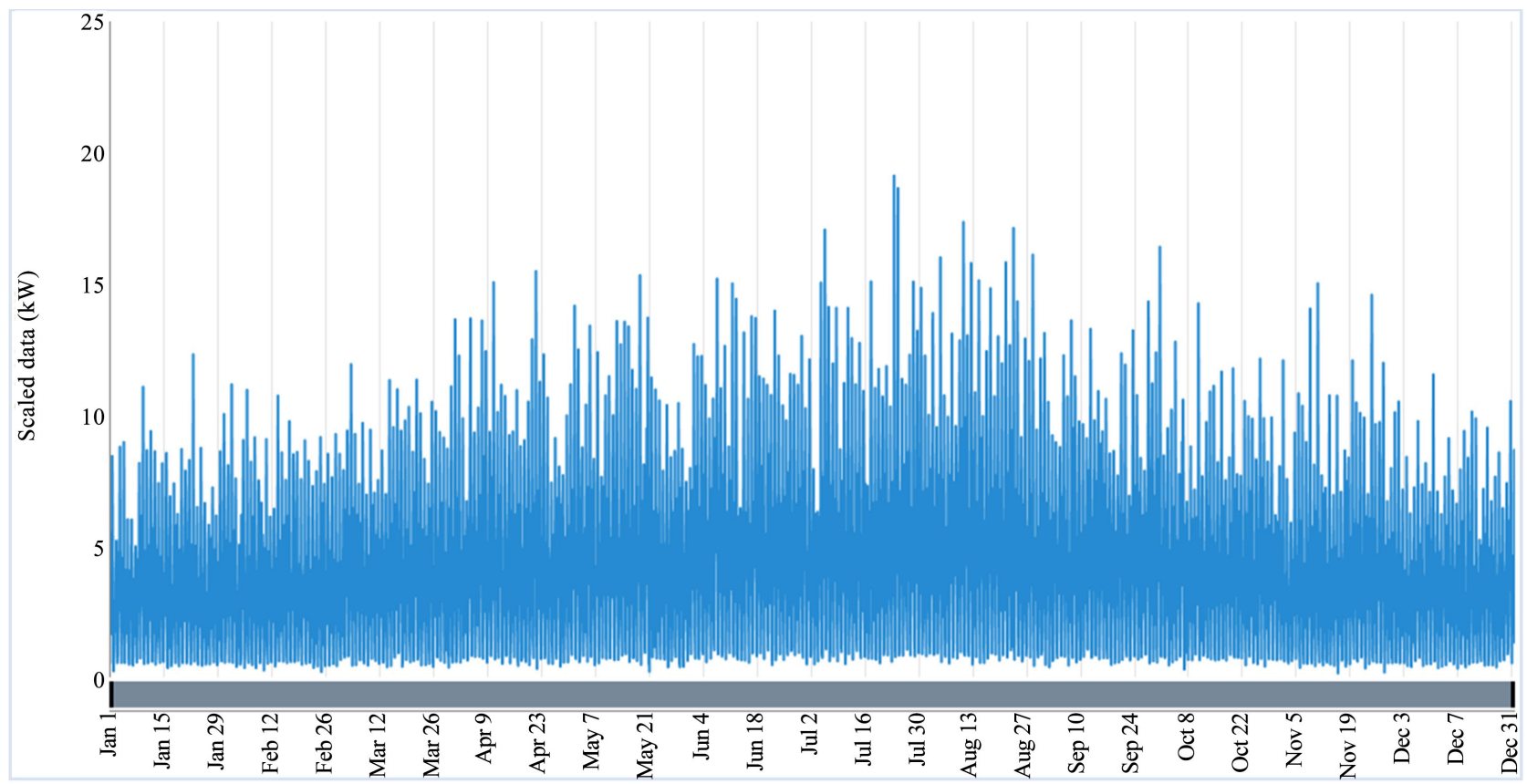

Figure 5. Hourly load.

In order to improve the technical efficiency of any PV system, solar panels should be oriented towards the sun and this boosts the amount of energy generated by the PV system. Because of this advantage, the tracking system can be considered to track the sun, and this increases the production during winter and summer. Figure 6 shows the schematics of different types of tracking systems used in PV application. Based on their control and adjustment they can be further classified. However, our study was limited to the following tracking systems: fixed angle tracker (FT), horizontal-axis PV tracker with continuous adjustment (HCA), horizontal-axis tracker with daily adjustment (HDA), horizontal-axis tracker with monthly adjustment (HMA), horizontal-axis tracker with weekly adjustment (HWA), and two or duel-axis tracker (DA). The aim is also to investigate the technical and economic aspects of this system.

After inputting initial configuration of the system, HOMER suggested some components for a particular tracking system for optimum system configuration, which has been listed in Table 1. Table 2 shows cost input for different components and Table 3 shows specification of these components.

In HOMER, there are two main economic factors used to rank different system configurations, these are the net present cost (NPC) or the life-cycle cost and levelized cost of energy (LCOE) [21]. NPC is defined as the present value of all system cost over the project's lifetime, minus the value of all revenues earned. Also, it can be calculated from Equation (1). The LCOE is the average cost in $\$ / \mathrm{kWh}$ of the actual consumed energy produced by the system and it can be calculated from Equation (2)

$$
N P C \$=\frac{C_{a n n, t o t}}{C R F\left(i, R_{p r o j}\right)}
$$




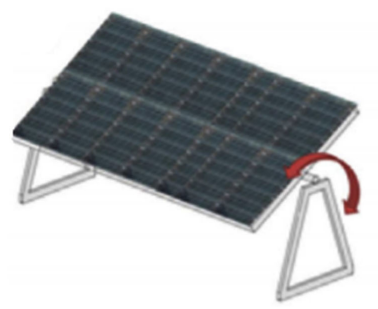

(a)

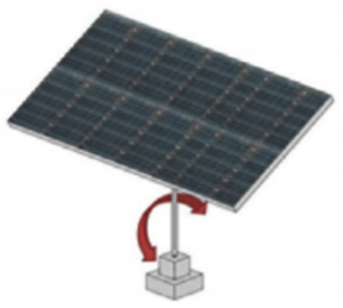

(b)

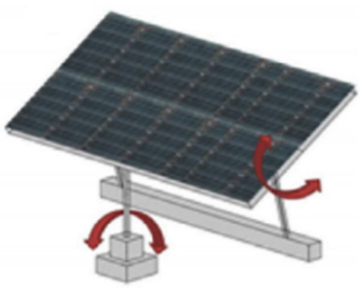

(c)

Figure 6. (a) horizontal PV tracker, (b) vertical PV tracker (c) two axis PV tracker [22].

Table 1. Proposed battery and converter size by homer for each tracker.

\begin{tabular}{ccc}
\hline Tracking system & Battery (Strings in Parallel) & Converter size $(\mathrm{kW})$ \\
\hline FT & 35 & 8.08 \\
HMA & 35 & 8.16 \\
HWA & 34 & 7.55 \\
HDA & 34 & 7.55 \\
HCA & 35 & 7.46 \\
VCA & 32 & 8.08 \\
DA & 30 & 8.08 \\
\hline
\end{tabular}

Table 2. Cost inputs for PV and trackers.

\begin{tabular}{ccc}
\hline NO & Tracking System & Capital Cost $(\$ / \mathrm{kWh})$ \\
\hline 1 & HMA, HWA, and HDA & 3563 \\
2 & HCA & 3870 \\
3 & VCA & 3255 \\
4 & DA & 4000 \\
\hline
\end{tabular}

Table 3. System components specifications.

\begin{tabular}{cccc}
\hline Component & Parameter & Value & Unit \\
\hline PV & Capacity & 1 & $\mathrm{~kW}$ \\
& Life time & 25 & Year \\
& Capital & 3000 & $\$$ \\
& Replacement & 3000 & $\$$ \\
Converter & O\&M & 10 & $\$ /$ year \\
& Capacity & 1 & $\mathrm{~kW}$ \\
& Life time & 15 & Year \\
& Efficiency & 90 & $\%$ \\
& Capital & 300 & $\$$ \\
Generator & Replacement & 300 & $\$$ \\
& Initial Capacity & 650 & $\$ / \mathrm{kW}$ \\
\hline
\end{tabular}




\section{Continued}

\begin{tabular}{cccc}
\hline Replacement & 650 & $\$ / \mathrm{kW}$ \\
O \& M & 0.03 & \$/op. hour \\
Life time & 15000 & hours \\
OFF hours/weekends & 10 & hours \\
Diesel Fuel Price & 0.13 & $\$ / \mathrm{L}$ \\
Life time & 10 & Year \\
Battery & Quantity per String & 1 & Batteries \\
& Bus Voltage & 12 & $\mathrm{~V}$ \\
Capital & 300 & $\$$ \\
Replacement & 240 & $\$$ \\
Oconomical parameters & Oroject life time & 25 & Year \\
& Real Discount Rate & 12 & \% \\
Pystem Size & 7.61 & $\mathrm{~kW}$ \\
& & 22 & $\mathrm{~kW}$ \\
\hline
\end{tabular}

where $i$ is the annual interest rate, $C_{a n n, t o t}$ represents the system total annualized cost, $R_{\text {proj }}$ is the project lifetime in years, and the capacity recovery factor (CRF) can be calculated by

$$
C R F=\frac{i(1+i)^{N}}{(1+i)^{N}-1}
$$

$i$ is the real discount rate and $\mathrm{N}$ refers to the number of years

$$
L C O E=\frac{C_{\text {ann,tot }}}{R_{\text {prim }}+R_{\text {tot, grid,sales }}}
$$

where $R_{\text {prim }}$ is the AC primary load in $\mathrm{kWh} /$ year and $R_{\text {tot,grid,sales }}$ is the total grid sales in $\mathrm{kWh} /$ year. $R_{\text {tot, grid,sales }}$ in this case is $=0$

An alternative economic performance measure that could be investigated by decision makers along with the NPC and the cost of energy is Return on Investment (ROI). It is the yearly cost savings relative to the initial or reference system. In HOMER, the ROI can be as follows:

$$
R O I=\frac{\sum_{i=0}^{R_{\text {proj }}} C_{i, \text { ref }}-C_{i}}{R_{\text {proj }}\left(C_{c a p}-C_{c a p, r e f}\right)}
$$

where $C_{i, \text { ref }}$ is the nominal annual cash flow for the base (reference) system; $C_{i}$ is the nominal annual cash flow for current system; $R_{\text {proj }}$ is the project lifetime in years; $C_{\text {cap }}$ is the capital cost of the current system; and $C_{\text {cap }, \text { ref }}$ is the capital cost of the base (reference) system. 


\section{Results and Discussions}

\subsection{System Electricity Production}

The findings in this area show that the DA tracking system has the highest amount of PV electricity production with a total amount of $21,143 \mathrm{kWh} / \mathrm{yr}$, which represents $52.1 \%$ of the total power generation of the DA hybrid PV system. This result indicates that the DA tracking system can produce $39 \%$ more power than FT, while VCA can produce up to $24 \%$ more power than FT. This is due to the flexibility of these trackers to follow the solar irradiation during the day. The power generation from HMA, HWA, and HDA has almost the same amount of power generation and the different time adjustments of the tilt angle has no significant impact on the output power. HCA produced only $2.5 \%$ more than the other three horizontal trackers as illustrated in Figure 7.

The excess electricity for all trackers is illustrated in Figure 8 and the DA tracking system, combined with the generator, demonstrated the highest excess electricity of $4176 \mathrm{kWh} / \mathrm{yr}$ followed by VCA with $2370 \mathrm{kWh} / \mathrm{yr}$.

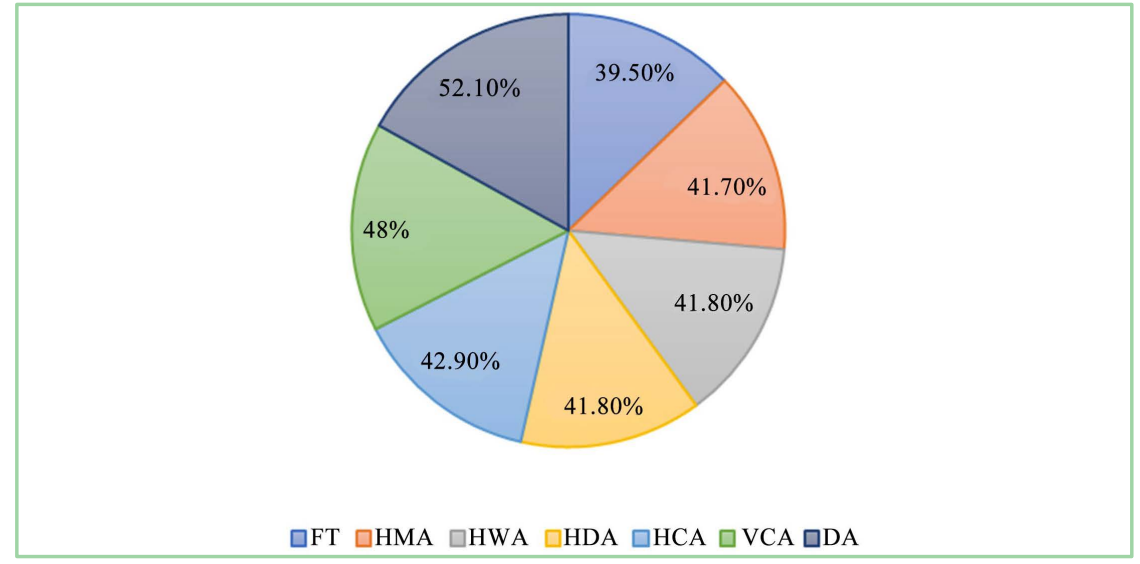

Figure 7. Annual contribution of PV output power in percentage for each system.

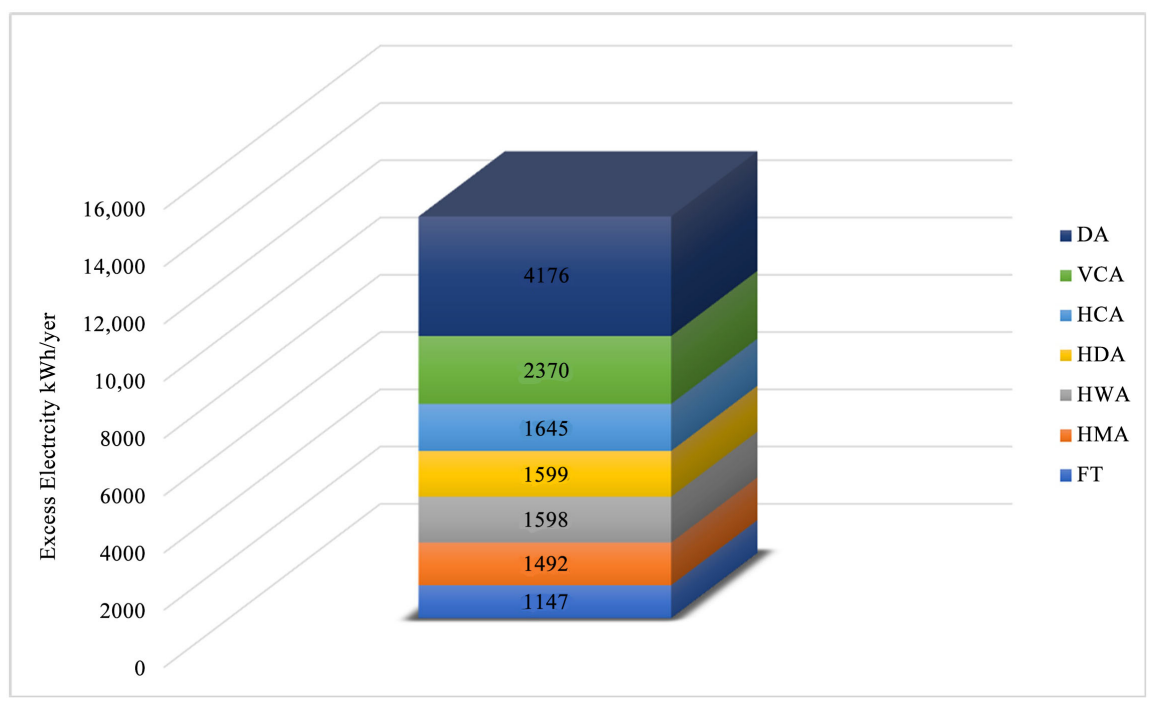

Figure 8. Contribution of different tracking systems to excess electricity. 


\subsection{Economic Analysis and Comparison of Different Systems}

The results in Figure 9 show that the system of FT had the lowest LCOE and NPC among all tracking systems except VCA, due to the low cost of the simple no tracking system along with the low cost of power production. However, the total fuel consumed by the generator was the highest with $7979 \mathrm{~L}$, due to the low electricity production from the FT PV system as shown in Figure 10. This also put the system with no tracker at the level of the highest $\mathrm{CO}_{2}$ emitter among other different tracking systems, as illustrated in the same figure. On the other hand, HCA showed the highest NPC and LCOE of $\$ 110,489.80$ and $0.4294 \$ / \mathrm{kWh}$, respectively. For HMA, HWA, and HDA the results presented were almost identical to each other in terms of NPC and cost of energy values despite the monthly, weekly, and daily adjustments of the tilt angle. Among all tracking systems, the VCA tracker showed an enhanced performance. Thus, in this scheme, $10 \%$ less $\mathrm{CO}_{2}$ emissions were produced by the generator compared to the FT and the yearly production from the PV system was $48 \%$ of the total electricity production. VCA also had the lowest NPC and LCOE among other tracking systems and the PV capacity factor was the highest after the DA tracker with $28.1 \%$. Despite the reasonable contribution of renewable power generation to the system by HCA tracker, the high costs of system components increased the cost of energy for this system compared to other PV trackers.

Figure 10 shows the inverse relation between the PV capacity factor $(\mathrm{CF})$ and $\mathrm{CO}_{2}$ emissions. It can be seen from this figure that the DA tracking system had the lowest $\mathrm{CO}_{2}$ emissions due to the high PV capacity factor which was $31.7 \%$, followed by the VCA with $28.1 \%$. These two types of tracking systems recorded the highest CF and lowest fuel consumption during the year compared to the FT system.

The comparison of economics features in HOMER allows users to compare a current system to any other system in the optimization results and calculate the payback or internal rate of return. In this case, the generator with the battery bank system was chosen as the base case system to compare it with all the other tracking systems to make the economic metrics meaningful.

In this study, the real discount rate of $12 \%$ and the project lifetime of 25 years have been considered as they are well accepted parameter among energy engineer and research community. Based on these values, HOMER calculated the discount factor and then the discounted cash flow for the system. Figure 11 shows a comparison of different economic metrics for each tracking system. As shown in this graph, the VCA system had the best present worth value and the lowest payback period among all the other trackers. Also, in comparison to the reference case, all the trackers demonstrated a positive ROI. This is generally refers to the high capital cost at the beginning of the project. The VCA system recorded the highest ROI, which makes it the most useful type since it makes a profit during the project lifetime. For the DA tracking system, despite the higher 
capital cost compared to the reference, the low ROI was mitigated by a greater efficiency all over the lifetime of the project, which is 25 years.

In HOMER, a discounted cash flow (DCF) is defined as the nominal cash flow discounted to year zero. Figure 12 shows a comparison of the cumulative discounted cash flow for all tracking systems throughout the project lifetime compared with the base case. This method was used to estimate the attractiveness of an investment opportunity in such cases. A DCF was done for all tracking systems and compared to (generator with battery bank system) the base case. Consequently, NPC for each system was founded by summing the yearly total discounted cash flows of the project lifetime. In Figure 12, VCA demonstrated the lowest NPC and LCOE of $\$ 102,357.10$ and $0.3979 \$ / \mathrm{kWh}$, respectively (followed by the FT and DA systems). In spite of the low capital cost at year zero for the base case, it had a very high NPC and LOCE compared to PV with diesel-battery system, considering all the different tracking systems.

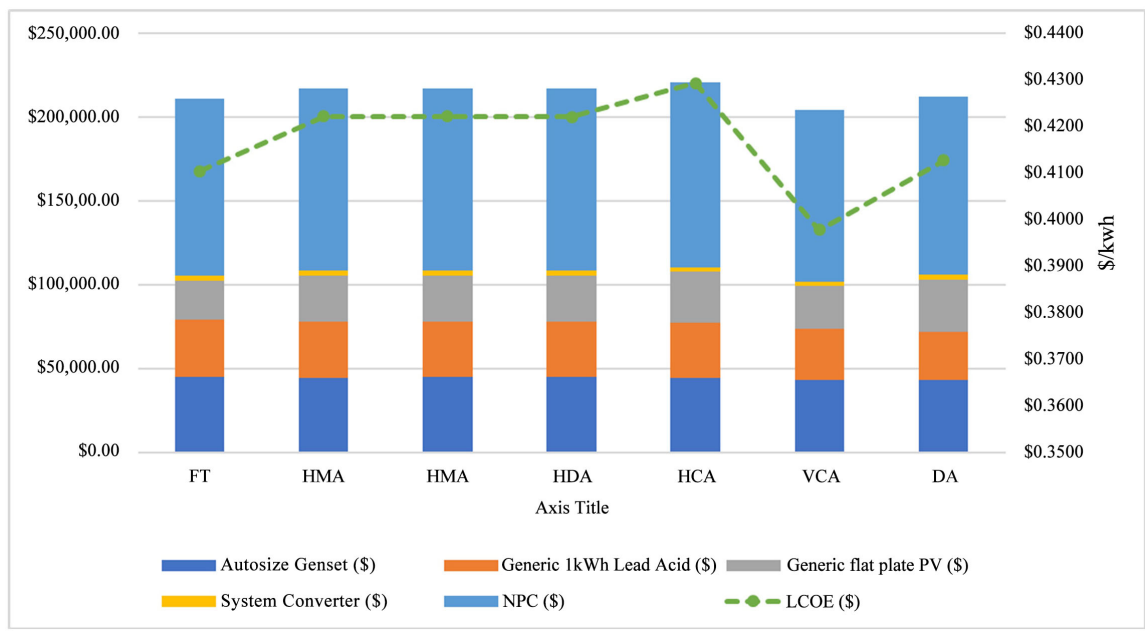

Figure 9. LCOE and NPC for different scenarios of trackers.

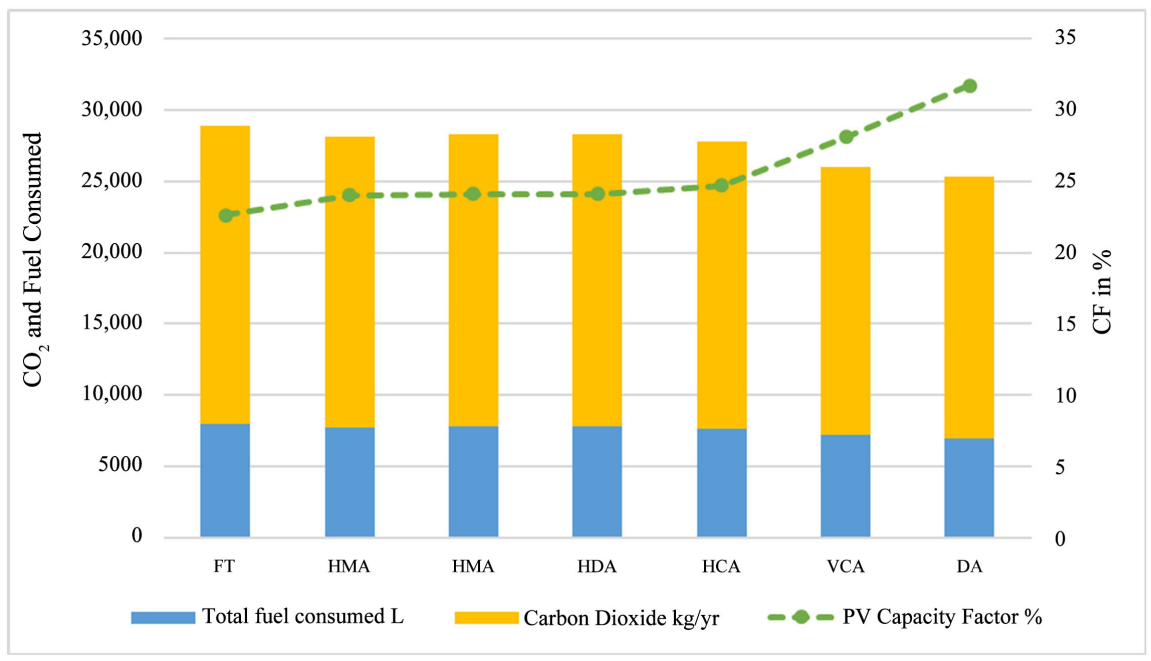

Figure 10. PV CF versus $\mathrm{CO}_{2}$ and fuel consumption. 


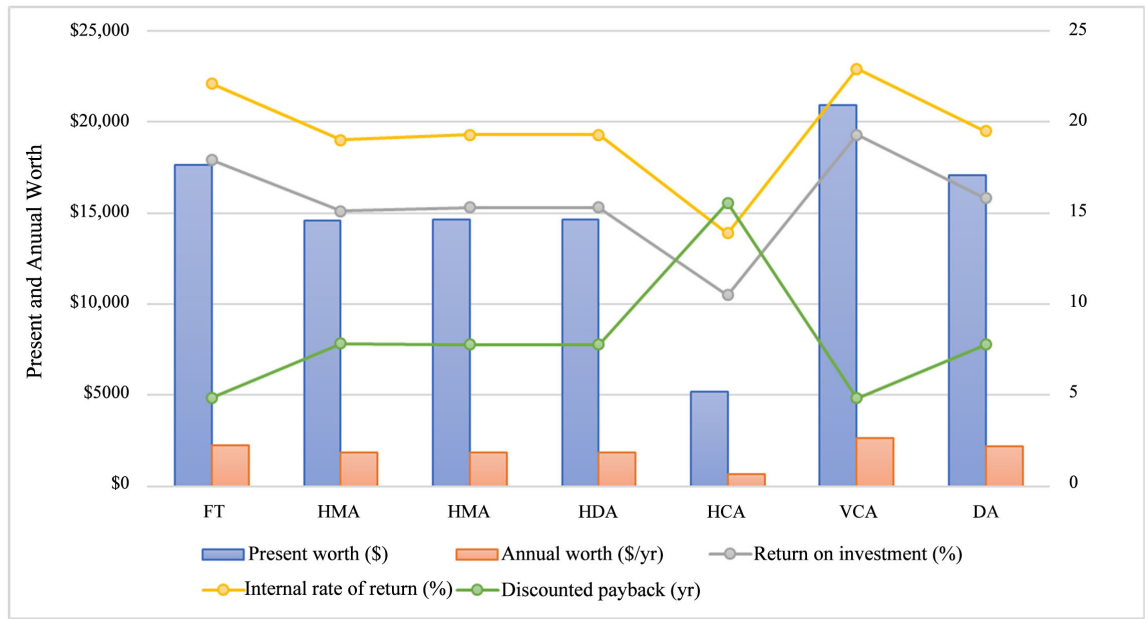

Figure 11. Economic comparison for different metrics.

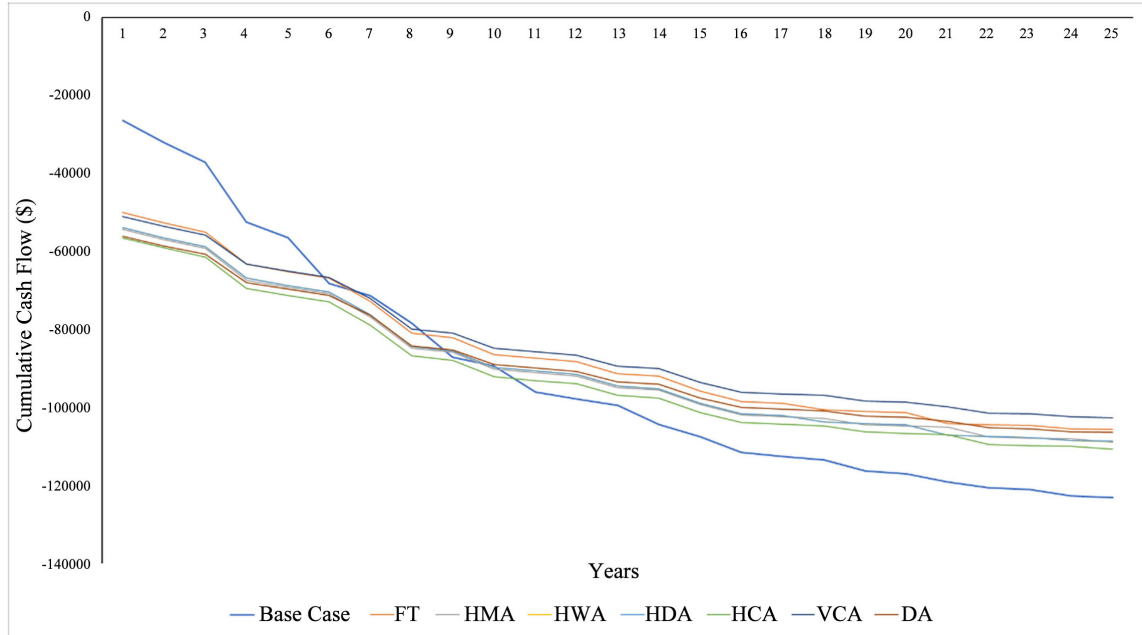

Figure 12. Cumulative discounted cash flow for all tracking systems and base case.

\subsection{Performance Analysis of VCA System}

Analysis from the previous section made it clear that VCA is the best among all the tracker system. In this section performance of this system will be analyzed. Figure 13 shows the AC primary load versus the generator and PV power output. This graph represents the annual power demand and electricity production using the VCA system since it is the best economic option for this study. The total PV output power in this figure is $18,707 \mathrm{kWh} / \mathrm{yr}$ and this amount represents $48 \%$ out of the total generation during the year. Also, the simulation shows that the electricity produced by the generator over the course of the year was $20,250 \mathrm{kWh} / \mathrm{yr}$. Therefore, the vast majority of power was obtained from the generator to meet the load demand and reduce the unmet energy of the system.

Figure 14 shows the monthly average electricity production from the VCA System. From this figure, the highest monthly averaged PV production occurred from June to August. Figure 15 illustrates the data map of the daily and seasonal PV power output during the year and this allows us to see the output power 
generated by the PV system more clearly. The sunshine reaches its peak between 10:30 am to 3:30 pm. During summer, the efficiency of the PV panels gets reduced due to the high temperature, which has an impact on the power produced by PV panels.

Figure 16 shows the relation between GHI and the renewable power output per year. This figure illustrates that the power generated by PV panels is heavily dependent on the GHI resources. It should be noted here that the total PV power generation will decrease because the modules will not perform as well as they did in the first year due to the solar panel degradation [23].

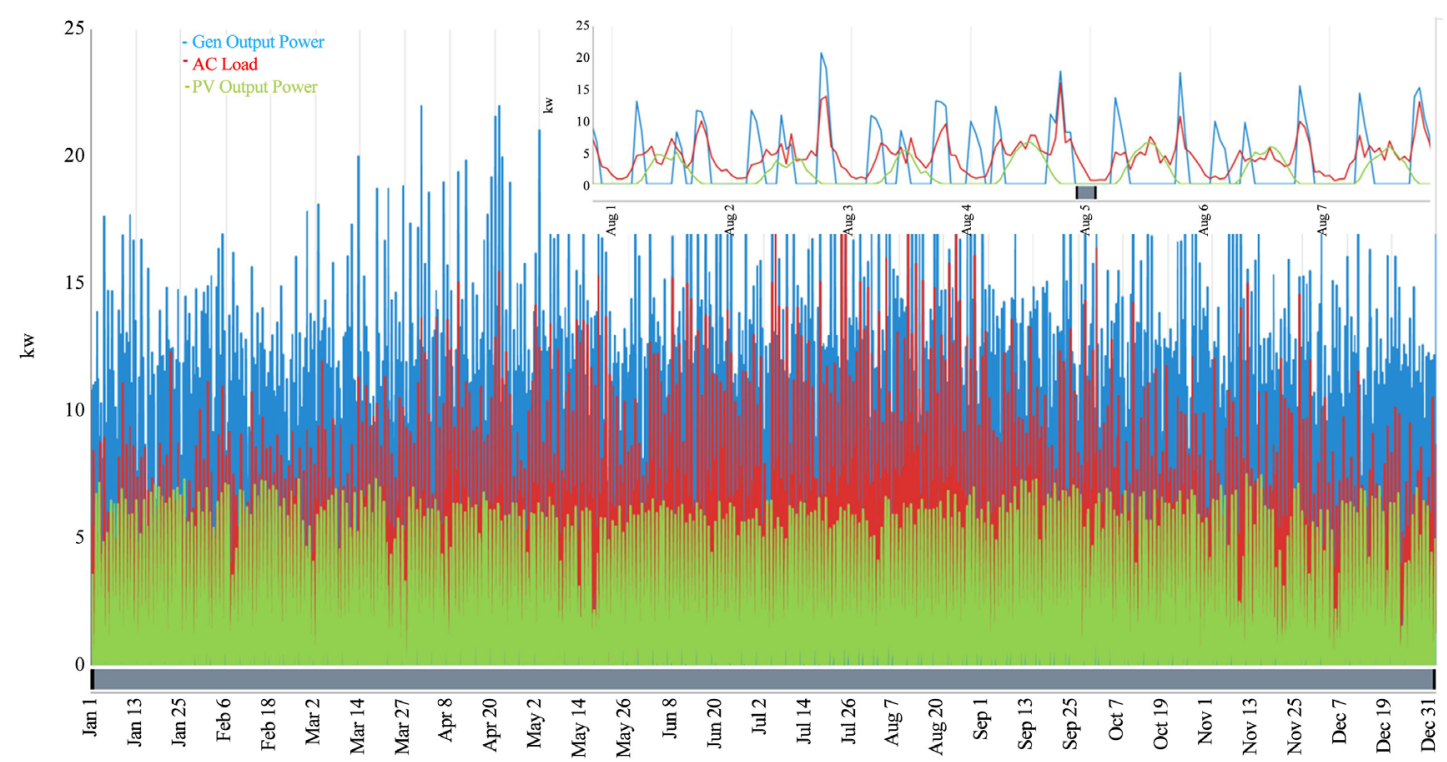

Figure 13. Annual ac primary load versus PV and generator electricity production in $(\mathrm{kW})$.

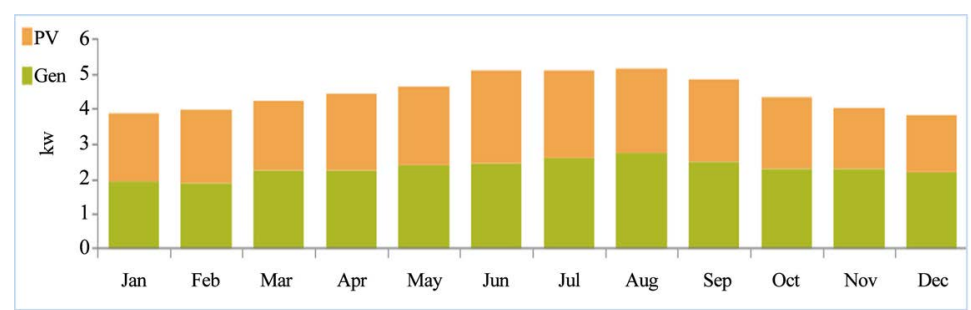

Figure 14. Monthly average electricity production for the VCA system.

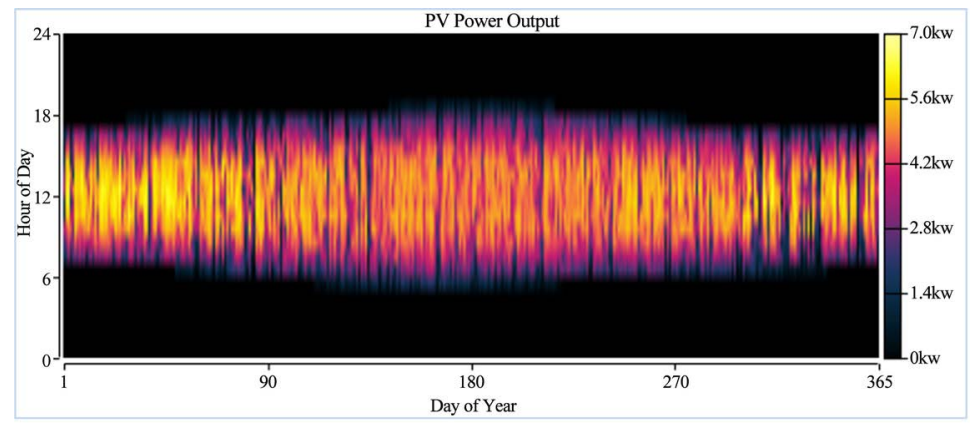

Figure 15. Daily pattern of the PV power output for the VCA system. 


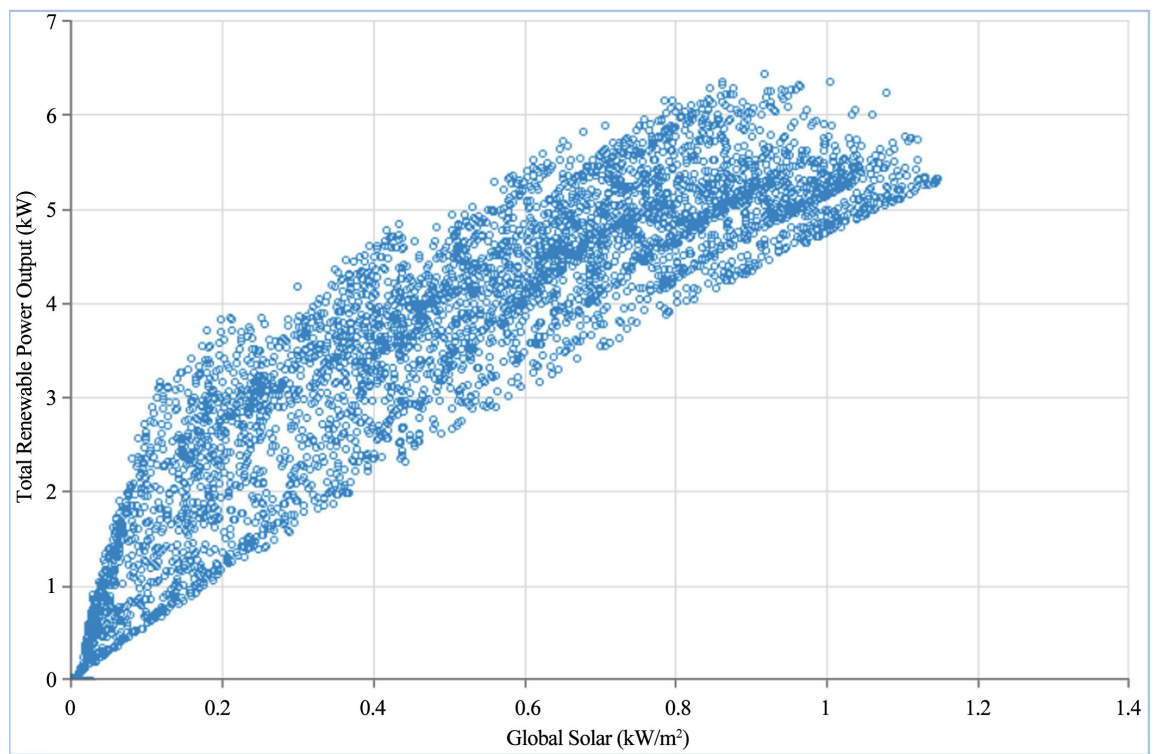

Figure 16. GHI versus total renewable power output for the VCA system.

\section{Conclusion}

This paper presents optimal sizing of a stand-alone PV-diesel-battery hybrid system for a $90 \mathrm{kWh} /$ day load. The optimization was done for different tracking systems, considering several technical and economic factors including levelized cost of energy (LCOE), net present cost (NPC), and photovoltaic power generation. The paper also presents the environmental impact of using different tracking systems. Investigations were carried out using HOMER software since it is superior to other software in managing different schemes and configurations of renewable energy sources and systems. The results show the potential of PV power production using different tracking systems, particularly the DA and VCA systems which stand out to be better than the rest. However, overall VCA has been found to be the best of all tracking systems. It has the lowest NPC which was around $\$ 102,357.10$ and an LCOE of $\$ 0.3979$. Furthermore, VCA having the highest ROI of $19 \%$ makes it the most useful option among all examined tracking systems. In the future research, performance analysis of a hybrid grid-connected system with different RE sources will be investigated for various locations with different metrological conditions.

\section{Conflicts of Interest}

The authors declare no conflicts of interest regarding the publication of this paper.

\section{References}

[1] Matar, W., Murphy, F., Pierru, A. and Riouxa, B. (2015) Lowering Saudi Arabia's Fuel Consumption and Energy System Costs without Increasing End Consumer Prices. Energy Economics, 49, 558-569. https://doi.org/10.1016/j.eneco.2015.03.019

[2] Ramli, M.A.M., Hiendro, A. and Al-turki, Y.A. (2016) Techno-Economic Energy 
Analysis of Wind/Solar Hybrid System : Case Study for Western Coastal Area of Saudi Arabia. Renewable Energy, 91, 374-385.

https://doi.org/10.1016/j.renene.2016.01.071

[3] Al Garni, H.Z., Awasthi, A. and Ramli, M.A.M. (2018) Optimal Design and Analysis of Grid-Connected Photovoltaic under Different Tracking Systems Using HOMER. Energy Conversion and Management, 155, 42-57.

https://doi.org/10.1016/j.enconman.2017.10.090

[4] IRENA. REthinking Energy 2017: Accelerating the Global Energy Transformation. http://www.irena.org//media/Files/IRENA/Agency/Publication/2017/IRENA_REthi nking_Energy_2017.pdf

[5] Renewables Global Status Report-REN21. (2017). http://www.ren21.net/wp-content/uploads/2017/06/GSR2017_Full-Report.pdf

[6] Alharthi, Y.Z., Siddiki, M.K. and Chaudhry, G.M. (2017) The New Vision and the Contribution of Solar Power in the Kingdom of Saudi Arabia Electricity Production. Ninth Annual IEEE Green Technologies Conference (GreenTech), Denver, 29-31 March 2017, 83-88. https://doi.org/10.1109/GreenTech.2017.18

[7] Saudi Electricity Company (2017) Annual Reports. https://www.se.com.sa/en-us/Pages/AnnualReports.aspx

[8] The Electricity \& Cogeneration Regulatory Authority (2017). http://www.ecra.gov.sa/en-us/dataandstatistics/pages/DataAndStatistics.aspx

[9] Zell, E., et al. (2015) Assessment of Solar Radiation Resources in Saudi Arabia. Solar Energy, 119, 422-438. https://doi.org/10.1016/j.solener.2015.06.031

[10] Hepbasli, A. and Alsuhaibani, Z. (2011) A Key Review on Present Status and Future Directions of Solar Energy Studies and Applications in Saudi Arabia. Renewable and Sustainable Energy Reviews, 15, 5021-5050.

https://doi.org/10.1016/j.rser.2011.07.052

[11] Ramli, M.A.M., Hiendro, A., Sedraoui, K. and Twaha, S. (2015) Optimal Sizing of Grid-Connected Photovoltaic Energy System in Saudi Arabia. Renewable Energy, 75, 489-495. https://doi.org/10.1016/j.renene.2014.10.028

[12] Ramli, M.A.M., Twaha, S., Ishaque, K. and Al-Turki, Y.A. (2017) A Review on Maximum Power Point Tracking for Photovoltaic Systems with and without Shading Conditions. Renewable and Sustainable Energy Reviews, 67, 144-159. https://doi.org/10.1016/j.rser.2016.09.013

[13] Almarshoud, A.F. (2016) Performance of Solar Resources in Saudi Arabia. Renewable and Sustainable Energy Reviews, 66, 694-701.

https://doi.org/10.1016/j.rser.2016.08.040

[14] Ramli, M.A.M., Prasetyono, E., Wicaksana, R.W., Windarko, N.A., Sedraoui, K. and Al-Turki, Y.A. (2016) On the Investigation of Photovoltaic Output Power Reduction Due to Dust Accumulation and Weather Conditions. Renewable Energy, 99, 836-844. https://doi.org/10.1016/j.renene.2016.07.063

[15] Kumari, J., Subathra, P., Moses, J.E. and Shruthi, D. (2017) Economic Analysis of Hybrid Energy System for Rural Electrification Using HOMER. International Conference on Innovations in Electrical, Electronics, Instrumentation and Media Technology (ICEEIMT), 978, 151-156. https://doi.org/10.1109/ICIEEIMT.2017.8116824

[16] Rey, A.L., Santiago, R.V.M. and Pacis, M.C. (2017) Modeling of a Hybrid Renewable Power System for Calayan Island, Cagayan Using the HOMER Software. IEEE 9th International Conference on Humanoid, Nanotechnology, Information Technology, Communication and Control, Environment and Management (HNICEM). 
https://doi.org/10.1109/HNICEM.2017.8269479

[17] Al Garni, H. and Awasthi, A. (2017) Techno-Economic Feasibility Analysis of a Solar PV Grid-Connected System with Different Tracking Using HOMER Software. 5th IEEE International Conference on Smart Energy Grid Engineering (SEGE), At Oshawa, 217-222. https://doi.org/10.1109/SEGE.2017.8052801

[18] Jiang, Q., Xue, M. and Geng, G. (2013) Energy Management of Microgrid in Grid-Connected and Stand-Alone Modes. IEEE Transactions on Power Systems, 28, 3380-3389. https://doi.org/10.1109/TPWRS.2013.2244104

[19] Sinha, S. and Chandel, S.S. (2014) Review of Software Tools for Hybrid Renewable Energy Systems. Renewable and Sustainable Energy Reviews, 32, 192-205. https://doi.org/10.1016/j.rser.2014.01.035

[20] Al-falahi, M.D.A., Jayasinghe, S.D.G. and Enshaei, H. (2017) A Review on Recent Size Optimization Methodologies for Standalone Solar and Wind Hybrid Renewable Energy System. Energy Conversion and Management, 143, 252-274. https://doi.org/10.1016/j.enconman.2017.04.019

[21] Jamalaiah, A., Raju, C.P. and Srinivasarao, R. (2017) Optimization and Operation of a Renewable Energy Based PV-FC-Micro Grid Using Homer. International Conference on Inventive Communication and Computational Technologies (ICICCT), Coimbatore, 10-11 March 2017, 450-455. https://doi.org/10.1109/ICICCT.2017.7975238

[22] Sinha, S. and Chandel, S.S. (2016) Analysis of Fixed Tilt and Sun Tracking Photovoltaic-Micro Wind Based Hybrid Power Systems. Energy Conversion and Management, 115, 265-275. https://doi.org/10.1016/j.enconman.2016.02.056

[23] Meyer, E.L. and Van Dyk, E.E. (2004) Assessing the Reliability and Degradation of Photovoltaic Module Performance Parameters. IEEE Transactions on Reliability, 53, 83-92. https://doi.org/10.1109/TR.2004.824831 